\title{
EDUCA-SAN: AÇÕES FORMATIVAS EM SEGURANÇA ALIMENTAR E NUTRICIONAL A PARTIR DE ESTRATÉGIAS VIRTUAIS COM AGENTES DA COMUNIDADE ESCOLAR
}

\author{
Juan Francisco Bacigalupo Araya ${ }^{1}$ \\ Erika Marafon Rodrigues Ciacchi ${ }^{2}$
}

\begin{abstract}
Resumo: O desenvolvimento da temática sobre Segurança Alimentar e Nutricional (SAN) no espaço escolar tem sido cada vez mais recomendado nas leis e diretrizes tanto nacionais como estrangeiras. A fim de fortalecer a rede de apoio entre universidades e comunidades escolares, o Centro Latino-Americano de Ciência e Tecnologia em Soberania, Segurança e Educação Alimentar e Nutricional da Região Sul - CeLASSAN/UNILA realizou um curso de atualização a distância, via plataforma Moodle, em parceria com os cursos de Nutrição de três universidades latinoamericanas, ofertado às comunidades escolares da Argentina, do Brasil, do Chile e da Colômbia. O curso foi iniciado com uma turma de 111 cursistas, apresentado em 60 horas com o desenvolvimento de dez módulos, com ênfase nos elementos socioculturais, políticos, nutricionais e promotores da saúde. Os cursistas apontaram, a partir da participação nos fóruns e da apresentação de um projeto em SAN, questões importantes a serem problematizadas no ambiente escolar que podem empoderar não apenas educadores, mas os próprios estudantes na promoção de uma alimentação saudável e segura enquanto um direito humano.
\end{abstract}

Palavras-chave: Educação a Distância. Tecnologias da Informação e das Comunicações. Educação em saúde. Segurança Alimentar e Nutricional.

\section{EDUCA-SAN: TRAINING ACTIONS ON FOOD AND NUTRITIONAL SECURITY FROM VIRTUAL STRATEGIES WITH SCHOOL COMMUNITY AGENTS.}

\begin{abstract}
The development of the Food and Nutritional Security (SAN) topic in the school environment is increasingly recommended in national and foreign laws and policies. Seeking to strengthen the support network between universities and school communities, the Latin American Center of Science and Technology in Food and Nutrition Sovereignty, Security and Education in the Southern Region - CeLASSAN/UNILA proposed an Interactive TeleEducation course offered to school communities in Argentina, Brazil, Chile and Colombia, via Moodle platform, with the support of undergraduate courses in Nutrition from three Latin American universities. The 60-hour, 10-module course began with 111 students, emphasizing socio-cultural, political, nutritional and health-promoting elements. The students pointed out, through participation in forums and the presentation of a project about SAN, important issues to be problematized in the school environment and that can empower, not only the teachers, but also the students themselves in promoting a healthy and safe diet as a human right.
\end{abstract}

Keywords: Interactive Tele-Education. School health promotion. Food and Nutrition Security

\footnotetext{
${ }^{1}$ Mestre em Educação em Ciências e Saúde (Nutes/UFRJ). Bolsista do CeLASSAN e consultor da Organización Panamericana de la Salud - OPAS-Chile, na área de Educação em Saúde. Bolsista da CeLASSAN. E-mail: jbacigalupoa@gmail.com

${ }^{2}$ Doutora em Educação (FE/UNICAMP). Coordenadora do Centro Latino-Americano de Ciência e Tecnologia em Soberania, Segurança e Educação Alimentar e Nutricional - CeLASSAN. Professora dos cursos de Saúde Coletiva e Desenvolvimento Rural e Segurança Alimentar da Universidade Federal da Integração Latino-Americana (Unila). Email: erika.ciacchi@unila.edu.br
} 


\title{
EDUCA-SAN: ACCIONES DE FORMACIÓN EN SEGURIDAD ALIMENTARIA Y NUTRICIONAL DESDE ESTRATEGIAS VIRTUALES CON AGENTES COMUNITARIOS ESCOLARES.
}

\begin{abstract}
Resumen: El desarrollo de la Seguridad Alimentaria y Nutricional (SAN) en el espacio escolar es cada vez más recomendado en las leyes y políticas nacionales y extranjeras. Buscando fortalecer la red de apoyo entre universidades y comunidades escolares, el Centro Latinoamericano de Ciencia y Tecnología en Soberanía, Seguridad y Educación Alimentaria y Nutricional de la Región Sur - CeLASSAN/UNILA propuso un curso de actualización a distancia, vía plataforma Moodle, con apoyo de los cursos de Nutrición de tres universidades latinoamericanas, ofertado a las comunidades escolares de Argentina, Brasil, Chile y Colombia. El curso, de 60 horas y diez módulos, inició con 111 estudiantes, dando énfasis a elementos socioculturales, políticos, nutricionales y promotores de la salud. Los estudiantes apuntaron, a través de la participación en foros y la presentación de un proyecto en SAN, ideas problematizadoras en el ambiente escolar y que pueden empoderar, no sólo a los educadores, sino que también a los propios estudiantes en la promoción de una alimentación saludable y segura como un derecho humano.
\end{abstract}

Palabras clave: Educación a distancia. Servicios de salud escolar. Seguridad Alimentaria y Nutricional.

\section{A extensão nos ambientes virtuais de aprendizagem}

O Educa-SAN é uma ação de extensão pensada para atender um público de educadores, que de uma forma ou outra, com mais ou menos intensidade, têm a segurança alimentar e nutricional (SAN) como tema que compõe o binômio educação-saúde impresso tanto nas políticas de saúde e educação quanto nos livros didáticos e práticas culturais, portanto, como atividade presente na agenda dos agentes promotores de saúde, no espaço escolar.

A ação foi desenvolvida por iniciativa do Centro Latino-Americano de Ciência e Tecnologia em Soberania, Segurança e Educação Alimentar e Nutricional da região Sul (CeLASSAN) criado na Universidade Federal da Integração Latino-Americana (UNILA) no ano de 2018 com apoio do Ministério de Ciência, Tecnologia e Inovações (MCTI). Com a missão de formar e articular, em perspectiva latino-americana e interdisciplinar, agentes da SAN com vistas ao fortalecimento de habilidades sociais, culturais e científicas para o aprimoramento e atualização de recursos de comunicação, educação e promoção em saúde, este Centro atua nas dimensões do ensino, da pesquisa e da extensão articuladas a diversos espaços: universidades, escolas, organizações da sociedade civil, órgãos públicos entre outros que demandem ações conjuntas pautadas no modelo progressista e, portanto, problematizador da educação.

Antes de aprofundarmos na ação propriamente do Educa-SAN, ressaltamos que a Extensão, um dos alicerces da universidade, tem se mostrado cada vez mais necessária e urgente junto a uma sociedade dinâmica que nos envolve, seja pelas transformações na esfera acadêmica, seja pela sua característica intrínseca de se lançar ao mundo para além dos muros universitários a fim de conhecer e compreender as exigências de diferentes grupos estreitando e fortalecendo vínculos com importantes grupos sociais, reconhecendo neles a singularidade de suas práticas e de 
suas habilidades numa construção não hierárquica ou autoritária, mas a partir de uma comunicação dialógica, comportando-se como se deve a extensão.

A extensão é uma ação viva, que não se interrompe, que agrega sujeitos, sujeitos participantes, ativos no e para o processo de produção de conhecimento, que não tende à estagnação para a interação constante e direta entre universidade e uma sociedade mais ampla que a comunidade estudantil e a comunidade científica ou mesmo da pesquisa convencional conduzida por docentes, muitas vezes, em âmbito individual.

Portanto, é por meio da atividade extensionista que as várias comunidades se encontram e processam juntas caminhos e aprendizagens valorizados e providos de sentido.

Nesse sentido, o Educa-SAN propõe ser um curso de atualização a distância, sabendo que essa estratégia permite melhor otimização do tempo, inclusão e acesso de agentes, considerando também a interação entre os participantes de territórios diversos, tendo finalizado em 2020 a sua segunda edição em caráter internacional, após ter sido em 2019 oferecido na instância municipal de Foz do Iguaçu/PR para professores da rede de ensino fundamental e médio. Vale lembrar que o ano de 2020 foi surpreendido pela pandemia da Covid19, que gerou, para muitas pessoas, uma condição de trabalho e estudo pautada mais expressivamente nas ferramentas virtuais.

As tecnologias de informação e comunicação (TICs) têm provocado uma transformação na relação do homem com o tempo-espaço, modificando as próprias bases das atividades cognitivas (SOUZA e LIRA, 2010). Esses avanços e inovações são percebidos em diferentes práticas e contextos sociais, sendo a Educação umas das principais áreas atingidas. A Educação a distância (EaD), mediada pelos Ambientes Virtuais de Aprendizagem (AVA) tem permitido a ampliação do acesso à formação, aperfeiçoamento e qualificação de profissionais.

A educação aberta e a distância surgem cada vez mais, no contexto da sociedade contemporânea, como uma modalidade de educação extremamente adequada e desejável para atender as novas demandas educacionais decorrentes das mudanças na nova ordem econômica mundial (BELLONI, 2008). Nesse cenário de mudanças, o professor e os demais agentes da escola assumem o desafio de inovar e qualificar suas práticas, agregando a ela temas de saúde e alimentação segura, como também nos ambientes virtuais de aprendizagem. Somado a isto, essa modalidade de ensino pode desenvolver o senso de compromisso onde o próprio agente da escola tem autonomia para se organizar e seguir seu próprio ritmo na aquisição e troca de conhecimento.

$\mathrm{Na} \mathrm{EaD}$ existe uma ressignificação dos tempos e espaços de formação uma vez que o ambiente de aprendizagem estará disponível de acordo com o tempo que o profissional puder lhe dedicar. Desta forma, alguns entraves materiais como deslocamento, reservas de salas de aula e 
quantidade de cursistas podem ser eliminados com o ambiente virtual de aprendizagem (FLORIANÓPOLIS, 2014).

A Lei de Diretrizes e Bases da Educação Nacional (LDB) de 1996, modificada em 2005 com o Decreto $\mathrm{N}^{0}$ 5.622, define educação a distância como:

Art. $1^{\circ}$ Modalidade educacional na qual a mediação didático-pedagógica nos processos de ensino e aprendizagem ocorre com a utilização de meios e tecnologias de informação e comunicação, com estudantes e professores desenvolvendo atividades educativas em lugares ou tempos diversos. (BRASIL, 2005).

Um aspecto para entender a dinâmica da prática de ensino na modalidade a distância é a caracterização destes ambientes virtuais entendidos como:

Espaços que se estabelecem por meio de tecnologias digitais, ultrapassando os limites físicos da sala de aula ou a interface de um portal, de forma que o importante são as interações e os diálogos que surgem entre os atores do processo que atuam no ambiente: professores, estudantes e monitores ou tutores (RECH, SOARES e VALENTINI, 2011, p 40).

A comunicação, o diálogo e a colaboração são, então, aspectos fundamentais na prática pedagógica de um curso de extensão a distância. A EaD é um meio interessante de formação quando bem planejado com o uso de linguagem e apoio adequados a essa modalidade formativa, com o cuidado de não se transportar o fazer da prática pedagógica presencial para o ambiente virtual, dadas as condições peculiares apresentadas por cada modelo, ainda que se aproximem.

\section{Processos educativos em segurança alimentar e nutricional: a importância de uma rede interdisciplinar}

Trabalhar questões relativas à temática de alimentação e nutrição no espaço escolar tem sido amplamente recomendado nas leis e diretrizes nacionais e estrangeiras. Diversas leis brasileiras fomentam a articulação da educação e o debate de questões sobre alimentação, promoção em saúde e soberania e segurança alimentar e nutricional. No panorama brasileiro, destacamos: a) a Portaria Interministerial $n^{\circ} 1010$ (BRASIL, 2006), que no seu artigo $5^{\circ}$ promove diversas ações, destacando "VIII. divulgar a experiência da alimentação saudável para outras escolas, trocando informações e vivências; [...] X. Incorporar o tema alimentação saudável no projeto político pedagógico da escola, perpassando todas as áreas de estudo e propiciando experiências no cotidiano das atividades escolares"; b) a Lei n 11.947 (BRASIL, 2009), que em seu artigo $2^{\circ}$ menciona "II - a inclusão da educação alimentar e nutricional no processo de ensino e aprendizagem, que perpassa pelo currículo escolar, abordando o tema alimentação e nutrição e o desenvolvimento de práticas saudáveis de vida, na perspectiva da segurança alimentar e 
nutricional”; c) o Plano Nacional de Segurança Alimentar e Nutricional - PLANSAN 2016-2019 (BRASIL, 2016), apresentando um conjunto de ações do governo federal que busca garantir a segurança alimentar e nutricional e o direito humano à alimentação adequada à população brasileira com destaque à meta 5.17, que busca "Apoiar 1.000 escolas por ano em ações de EAN , priorizando as escolas que aderiram ao PSE $^{3 ”}$ e, por fim, d) a Lei N. 13.666, de 16 de maio de 2018, que "altera a Lei n 9.394, de 20 de dezembro de 1996 (Lei de Diretrizes e Bases da Educação Nacional), para incluir o tema transversal da educação alimentar e nutricional no currículo escolar" (BRASIL, 2018).

O chamamento de ordem política para ações educativas em alimentação e nutrição no âmbito escolar tem também alcance latino-americano. Na Argentina foi aprovada a Lei № 26.396 de 3 de setembro de 2008 que estabelece as diretrizes para a prevenção e controle dos transtornos alimentares, garantindo com ações interministeriais a incorporação da educação alimentar e nutricional em todos os níveis do sistema educativo, a formação de professores, trabalhadores sociais, da saúde e demais agentes comunitários na compreensão da problemática alimentar (Artigo $6^{\circ}$ ), ainda a lei determina que cantinas e outros estabelecimentos de venda escolares devem oferecer produtos que compreendam a alimentação saudável e variada (Artigo 9º) (ARGENTINA, 2008).

No ano seguinte, a Colômbia publica a Lei № 1.355 de 14 de outubro de 2009 que define a obesidade e as doenças crônicas não transmissíveis associadas a ela como prioridade de saúde pública, sendo que em seu artigo $4^{\circ}$ estabelece "Estratégias para promover uma alimentação balanceada e saudável" tendo as instituições de ensino do país como espaços promotores de práticas alimentares desejáveis, recomendando-se a implementação de programas educativos em nutrição que respeitem e valorizem as diversas características culturais (COLOMBIA, 2009).

No Chile foi aprovada no ano de 2012 a lei No 20.606 que dispõe sobre composição nutricional dos alimentos e sua publicidade. Especificamente no artigo $4^{\circ}$ se estabelece que:

Os estabelecimentos de creche, ensino fundamental e médio, do país devem incluir, em todos os níveis e métodos de ensino, atividades didáticas e físicas que contribuam para desenvolver hábitos de alimentação saudável e alertar sobre os efeitos nocivos de uma dieta excessiva em gorduras, gorduras saturadas, açúcares, sódio e outros nutrientes cujo consumo em determinadas quantidades ou volumes pode representar um risco para a saúde (CHILE, 2012. Tradução nossa).

\footnotetext{
${ }^{3}$ PSE - Programa Saúde na Escola, instituído pelo Decreto No. 6.286 de 5 de dezembro de 2007, com a finalidade de impulsionar ações de prevenção, promoção e atenção à saúde para o alcance de uma formação integral dos estudantes da rede pública de educação básica.
} 
No âmbito internacional existem ainda diversos acordos, planos e leis que tratam da questão alimentar e nutricional que se relacionam com o setor educacional. Por exemplo, nos Objetivos de Desenvolvimento Sustentável (ONU, 2018), encontramos 17 tópicos que são de interesse mundial, com ênfase aos números 2 (“Fome zero e agricultura sustentável: Acabar com a fome, alcançar a segurança alimentar e melhoria da nutrição e promover a agricultura sustentável”) e 3 ("Saúde e bem-estar: assegurar uma vida saudável e promover o bem-estar para todas e todos, em todas as idades") que dialogam com ações formativas em SAN.

No âmbito de uma ação multilateral internacional, o Brasil lançou em setembro de 2011, durante o governo da presidenta Dilma Rousseff, o $1^{\circ}$ Plano de Ação Nacional vinculado à Parceria para Governo Aberto (Open Government Partnership - OGP) contendo os compromissos que representam os quatro princípios do Governo Aberto: transparência, participação cidadã, prestação de contas, tecnologia e inovação com processo de definição dos temas para o $5^{\circ}$ Plano aberto à sociedade civil para contribuição dessa construção (BRASIL, 2021).

Um dos temas de interesse ao OGP, também em consonância com os Objetivos do Desenvolvimento Sustentável (ODS), foi a Segurança Alimentar e Nutricional refletida no $4^{\circ}$ Plano de Ação (BRASIL, 2018) firmado no Compromisso 4, sob coordenação do Ministério do Desenvolvimento Social:

Implementar ações de formação voltadas aos gestores públicos e à sociedade civil com o objetivo de ampliar o reconhecimento do Direito Humano à Alimentação Adequada (DHAA) e fortalecer o controle social da Política de Segurança Alimentar e Nutricional (SAN) [...] Objetivo Agenda 2030: 2 - Acabar com a fome, alcançar a segurança alimentar e melhoria da nutrição e promover a agricultura sustentável (Brasil, 2018, p. 26).

Como parte dos resultados das ações desse Plano foram mapeados, com base em consultoria contratada, cursos de educação a distância para a promoção e formação em Segurança Alimentar e Nutricional em um documento apresentado pelo Ministério da Cidadania ${ }^{4}$ : Governança em segurança alimentar e nutricional/ Universidade Federal do Rio Grande do Sul UFRGS (30h), FormaSAN Online/Universidade Federal de Santa Catarina - UFSC e Teia de Articulação pelo Fortalecimento da Segurança Alimentar e Nutricional - TearSAN (curso permanente), Orienta PLANSAN - Curso de Orientações para a Elaboração dos Planos Estaduais, Distrital e Municipais de Segurança Alimentar e Nutricional/Ministério da Cidadania (40h), Ideias na Mesa - Educação Alimentar e Nutricional: uma estratégia para a promoção do direito humano à alimentação adequada/Ministério da Cidadania (20h), Dialogando sobre o Direito Humano à Alimentação Adequada, no contexto da Atenção Básica à Saúde/Rede de Alimentação e Nutrição

4 Disponível em: https://www.gov.br/cgu/pt-br/governo-aberto/a-ogp/planos-de-acao/4o-plano-de-acaobrasileiro/compromisso-4-docs/levantamento-de-cursos-de-ead-sisan.pdf . Acesso em: 11 de dezembro de 2020. 
do Sistema Único de Saúde, Guia Alimentar para a População Brasileira: novos princípios e recomendações/ Rede de Alimentação e Nutrição do Sistema Único de Saúde, Promoção da alimentação saudável na Atenção Básica/Universidade Aberta do Sistema Único de Saúde (30h), Cantinas Escolares Saudáveis: promovendo a alimentação saudável/Rede de Alimentação e Nutrição do Sistema Único de Saúde e o curso Especialização em Segurança Alimentar e Nutricional/Universidade da Integração Internacional da Lusofonia Afro-Brasileira - UNILAB e Universidade Estadual Paulista - UNESP.

Dessas ações acima duas são oriundas de pesquisas da região Sul do Brasil financiadas pela chamada CNPq/MCTI No 16/2016 - Segurança Alimentar e Nutricional no âmbito da Unasul que exigia como um dos objetivos fomentar ações na temática de SAN motivando interações entre instituições de ensino, pesquisa e extensão e sistemas públicos de educação e outras comunidades garantindo assim a participação e controle social. Tantas outras ações foram realizadas nesse âmbito da formação, da oferta de cursos às comunidades nos seus mais variados contextos. O CeLASSAN apoiou, nos meses de março e abril de 2020, a apresentação de 27 equipes de pesquisadores da região Sul com os resultados dos seus projetos vinculados a essa Chamada pela plataforma da NutriSSAN/RNP, por webconferência ${ }^{5}$, a partir da qual foi possível conhecer em profundidade o escopo e o desenvolvimento de cada pesquisa.

Nessa agenda de apresentações, foram mostradas diversas ações de formação em SAN propostas por esse grupo de pesquisadores, muitas realizadas na modalidade presencial com públicos diversos na oferta de cursos de SAN na produção de queijo colonial artesanal, cursos sobre territorialidade, políticas de SAN, cultura alimentar, boas práticas de fabricação e cooperativismo, formação permanente em Soberania e Segurança Alimentar e Nutricional (SSAN), Agroecologia e Saúde Popular, cursos de boas práticas de fabricação e conserva, boas práticas de manejo na apicultura, curso de formação em plantas bioativas e agricultura ecológica, entre outros. Já na modalidade a distância exemplificamos cursos para formação sobre mercados institucionais PAA (Programa de Aquisição de Alimentos) e PNAE (Programa Nacional de Alimentação Escolar) com foco nas compras da Agricultura Familiar, curso sobre agroecologia e sociobiodiversidade, SAN e cantinas escolares, alguns deles, como mencionamos, registrados no documento apresentado pelo Ministério da Cidadania.

Essas ações, vinculadas aos projetos da Chamada CNPq/MCTI N 16/2016, podem ser consultadas a partir de um livreto ${ }^{6}$ que aborda em detalhes as equipes e objetivos das pesquisas.

\footnotetext{
${ }^{5}$ https://conferenciaweb.rnp.br/webconf/nutrissanunila

${ }^{6}$ Disponível em: http://redelassan.com.br/livreto-da-rede-ssan-al/ . Acesso em: 09 de dezembro de 2020.
} 
Fortalecem e confirmam estas estratégias de segurança alimentar e nutricional no âmbito escolar, estendidas à formação do professor, as conferências internacionais de promoção em saúde, desde a primeira conferência resultando na Carta de Ottawa (1986), que recomenda a promoção da saúde, por meio de uma comunicação efetiva que intensifique abordagens educativas e habilidades vitais, até a Declaração de Xangai (2016) incentivando a implementação de ações para o letramento em saúde em ambientes escolares garantindo escolhas saudáveis.

A Educação Alimentar e Nutricional (EAN) é um campo de conhecimento e de prática contínua e permanente, transdisciplinar, intersetorial e multiprofissional que visa promover a prática autônoma e voluntária de hábitos alimentares saudáveis, no contexto da realização do Direito Humano à Alimentação Adequada e da garantia da Segurança Alimentar e Nutricional (BRASIL, 2012). Nessa linha, a formação permanente de agentes atuantes na escola é parte das ações recomendadas pelas diversas leis nacionais que regulamentam a SSAN. E mais recentemente, foi criada a Lei $\mathrm{N}^{\mathrm{o}} 13.666$ de 16 de maio de 2018 que vem alterar a Lei $\mathrm{N}^{\circ} 9.394$ de dezembro de 1996 (Lei de Diretrizes e Bases da Educação Nacional) para incluir a Educação Alimentar e Nutricional junto aos demais temas previstos na LDB, reforçando uma diretriz da Lei $\mathrm{n}^{\mathrm{o}} 11.947$ que prevê "a inclusão da educação alimentar e nutricional no processo de ensino e aprendizagem, que perpassa pelo currículo escolar, abordando o tema alimentação e nutrição e o desenvolvimento de práticas saudáveis de vida, na perspectiva da segurança alimentar e nutricional".

$\mathrm{O}$ ato de ingerir alimentos torna-se um fato cultural que vai além da nutrição, tornando-se um complexo sistema de relações socioculturais, de coesão comunitária e de atividade social. Nesse sentido, Contreras e Gracia Arnaiz (2011) argumentam que por trás de cada alimento há uma história, que fala sobre as condições climáticas e geográficas necessárias para que o alimento seja produzido, uma história que nos conta o desenvolvimento tecnológico de um grupo para obter o alimento e encontrar a melhor maneira de torná-lo apto para o consumo. A maneira pela qual um grupo come sua comida é, ao mesmo tempo, a história de como eles veem o mundo.

Considerando a complexidade sociocultural da alimentação e da educação, fundamentamos nosso projeto na reflexão teórica de Paulo Freire (1996), quem propõe que no centro das discussões sobre formação devemos considerar elementos até então marginalizados pela suposta neutralidade dos currículos acadêmicos, como: a participação das comunidades interna e externa à escola, a valorização da cultura popular, a democratização do conhecimento, a autonomia da escola em se fortalecer como espaço de formação de sujeitos autônomos, politizados e críticos, mediados pelo diálogo horizontal na relação educador-educando. Assim, Freire afirma: 
"Na formação permanente dos professores, o momento fundamental é o da reflexão crítica sobre a prática. [...] O próprio discurso teórico, necessário à reflexão crítica, tem de ser de tal modo concreto que quase se confunde com a prática" (FREIRE, 1996, p.39, grifo nosso).

Nessa linha, Vygotsky (1991) já assegurara que cada pessoa é um ser social, relacional e participante de um processo histórico e a construção do conhecimento se dá por meio dessa comunicação. Mas, como se dá este interagir em ambientes virtuais? A reflexão crítica proposta por Freire? Segundo Belloni (2008, p. 54) "a interação com o professor é indireta e tem que ser mediatizada por uma combinação dos mais adequados suportes técnicos de comunicação". Nessa linha, os AVA têm propiciado possibilidades de desenvolvimento da relação entre tutor-alunos e alunos-alunos, fortalecendo no estudante a capacidade de construir sua aprendizagem com o apoio de suportes tecnológicos interativos.

Boog (2010) nos alerta para a construção de programas de promoção da alimentação saudável, viáveis e eficazes, sugerindo que eles sejam pautados em diagnósticos que lancem luzes não só no consumo alimentar, mas sobre a cultura e as condições de vida dos grupos humanos, de forma tal que eles possam ser planejados considerando necessidades e valores da comunidade. Nesse sentido, estamos penetrando no universo escolar, um subcampo social, mas não menos expressivo e não menos plural de práticas culturais que o grande campo da realidade social conformada por todos demais micros espaços delineados por características que os predefinem.

O ambiente escolar reúne as temáticas da alimentação, da segurança alimentar e nutricional observadas tanto na fala dos professores em sala de aula, apoiados por livros didáticos quanto na orientação dada pelos cozinheiros, sendo estes, de acordo com Gonzalez-Chica e cols. (2013), agentes promotores de saúde finais e fundamentais na concretização das ações postas pela Política de Alimentar Escolar, quando preparam e oferecem os alimentos aos escolares.

Para tanto, esta ação registrada e apoiada pela Pró-Reitoria de Extensão da UNILA, já em sua segunda edição, tem como objetivos: a) problematizar temas de soberania, segurança e educação alimentar e nutricional entre agentes de comunidades escolares na América Latina por meio de um curso virtual realizado via plataforma Moodle; b) proporcionar aos professores e demais agentes de escolas do ensino fundamental oportunidades de fortalecimento coletivo para o desenvolvimento das práticas educativas relacionadas às temáticas de soberania, segurança e educação alimentar e nutricional no contexto dos livros didáticos, das práticas socioalimentares e culturais e dos debates governamentais, internacionais e sociais; c) apoiar a criação de projetos sobre soberania, segurança e educação alimentar e nutricional a serem desenvolvidos nos espaços escolares pelos cursistas participantes do projeto. 


\section{Percurso Metodológico}

O curso virtual internacional Educa-SAN foi inteiramente pensando e desenvolvido usando a estratégia de educação a distância, via Moodle, como parte do planejamento da equipe organizadora. A utilização das TICs tem alterado os ambientes sociais a ponto de se fortalecerem os canais de comunicação e interação social e, no que diz respeito à educação, tem permitido explorar novas formas de ensino-aprendizagem para a aquisição de conhecimentos e, ainda, tem permitido desenvolver capacidades e aptidões no uso e apropriação de novas tecnologias como as plataformas virtuais.

São muitas as plataformas virtuais de ensino, sendo uma delas o Moodle, sistema de administração de cursos por meio de um ambiente virtual aprendizagem (AVA), que ajuda professores, tutores e alunos a criar comunidades de aprendizagem online. De acordo com González (2013):

Este sistema foi criado por Martin Dougiamas, que baseou seu projeto nas ideias do construtivismo na pedagogia que afirmam que o conhecimento é construído na mente do aluno em vez de ser transmitido inalterado de livros ou ensinamentos e na aprendizagem colaborativa ( p.23).

$\mathrm{Na}$ EaD combinam-se atividades desenvolvidas para o ensino e aprendizagem a distância, geralmente on-line (como as videoaulas), com atividades em que o aluno estuda individualmente ou virtualmente com outros (comentários no foro, leitura de textos, etc.) (SILVA e MACIEL, 2015). Esses dois exemplos são parte das chamadas estratégias assíncronas, ou seja, onde não é necessário que emissor e receptor coincidam em um mesmo intervalo de tempo ou que seja gerada uma interação instantânea. Eles estão necessariamente localizados em um espaço físico, lógico e tecnológico que permite o acesso e posteriormente o uso das informações. O seu valor é inegável na educação a distância, pois permite o acesso diferido às informações apresentadas, proporcionando uma componente flexível de utilização do aluno, absolutamente necessária devido às características especiais apresentadas pelos alunos que estudam nesta modalidade virtual (pandemia, teletrabalho, limitação de tempo, família, etc.).

Por outro lado, as estratégias síncronas apresentam a característica de terem a participação e o tempo compartilhados para o remetente e o receptor da mensagem no processo de comunicação, ou seja, é necessário que ambos estejam presentes ao mesmo tempo, para que o processo seja efetivo, o que geralmente acontece, por exemplo, no chat ou em videoconferências. Este tipo de método desempenha um papel socializante muito importante, pois esta interação tende a evitar o isolamento do aluno da modalidade virtual, por isso foi considerado dentro do planejamento metodológico do nosso curso. 
Apesar de serem momentos e estratégias diferentes, o objetivo é que as atividades síncronas e as assíncronas sejam complementares e promovam uma educação mais eficiente, interessante e personalizada (PORVIR, 2013). O curso foi planejado a partir da experiência do Educa-SAN 2019, sendo ocupado o primeiro semestre de 2020 para criação de novos materiais, edição das videoaulas, criação de legendas (em espanhol quando necessário), planejamento dos módulos e oferta de materiais no AVA. Durante o segundo semestre de 2020 foi criada uma turma com vagas disponibilizadas para profissionais que atuavam no âmbito de escolas de ensino fundamental e médio de Argentina, Brasil, Chile e Colômbia.

Os interessados preencheram um formulário de inscrição, totalizando mais de 200 registros; porém, por ser um curso pensado com tutoria, somente foram aceitos 111 cursistas dos quatro países citados acima.

Foram ofertados pela equipe do projeto nove módulos problematizadores, com dedicação estimada do estudante de 6 horas para as videoconferências e 6 horas para as videoaulas. Três módulos foram videoconferências síncronas, um teve um vídeo de apresentação geral sobre o assunto e os outros cinco foram preparados com outros tantos vídeos, sendo um geral e introdutório para o conteúdo e um vídeo específico para cada país. Após a visualização das aulas, os estudantes deviam responder cinco questões sobre o tema em consonância com a realidade do espaço escolar no qual eles atuam e contexto do seu país. Os módulos do curso e os docentes convidados foram os seguintes (quadro 1):

Quadro 1- Módulos Problematizadores

\begin{tabular}{|c|c|}
\hline MODULO E TEMA* & DOCENTES RESPONSÁVEIS \\
\hline $\begin{array}{l}\text { 1. Videoconferencia sincrónica: Presentación del } \\
\text { curso, equipo docente y estudiantes. } \\
\text { Conferencia: } \\
\text { Importancia de la seguridad alimentaria y nutricional } \\
\text { en el espacio escolar: impactos de la pandemia. }\end{array}$ & $\begin{array}{c}\text { Erika Marafon Rodrigues Ciacchi (Brasil) } \\
\text { Juan Bacigalupo Araya (Brasil) } \\
\text { Sara Eloísa del Castillo (Colombia) }\end{array}$ \\
\hline $\begin{array}{l}\text { 2. Alimentación y cultura: las transformaciones de los } \\
\text { alimentos, de los gustos y del cuerpo. }\end{array}$ & \begin{tabular}{|c} 
Amábela de Avelar Cordeiro (Brasil) \\
Patricia Gálvez (Chile) \\
Luz Marina Arboleda y Laura Salazar (Colombia) \\
Delia Nin (Argentina) \\
Amábela de Avelar Cordeiro (Brasil)
\end{tabular} \\
\hline $\begin{array}{l}\text { 3. Nutrientes esenciales: La utilización biológica de } \\
\text { los alimentos y problemas de salud como resultado de } \\
\text { las prácticas de alimentación inadecuadas. }\end{array}$ & $\begin{array}{c}\text { Karen Basfi-fer (Chile) } \\
\text { Gloria Deossa (Colombia) } \\
\text { Ana Asaduroglu (Argentina) } \\
\text { Glenys Mabel Caballero Córdoba (Brasil) }\end{array}$ \\
\hline
\end{tabular}




\begin{tabular}{|l|c|}
\hline $\begin{array}{l}\text { 4. Videoconferencia sincrónica: } \\
\text { Políticas públicas sobre seguridad alimentaria y } \\
\text { nutricional en el espacio escolar. }\end{array}$ & $\begin{array}{c}\text { Silvia Aparecida Zimmermann (Brasil) } \\
\text { Verónica Risso Patrón (Argentina) } \\
\text { Gustavo Cediel (Colombia) } \\
\text { Lorena Rodríguez (Chile) }\end{array}$ \\
\hline $\begin{array}{l}\text { 5. Guías alimentarias para la población en América } \\
\text { Latina como estrategia de comunicación, educación y } \\
\text { promoción en salud. }\end{array}$ & $\begin{array}{c}\text { Carmen Suárez (México) } \\
\text { Bernardita Daniels (Chile) } \\
\text { Luz Marina Arboleda (Colombia) } \\
\text { Florencia González (Argentina) } \\
\text { Regina Maria Ferreira Lang (Ferreira) }\end{array}$ \\
\hline $\begin{array}{l}\text { 6. Rotulación y etiquetado nutricional como } \\
\text { herramienta de seguridad alimentaria y nutricional. }\end{array}$ & $\begin{array}{c}\text { Carmen Gloria González (Chile) } \\
\text { Paola Cáceres (Chile) }\end{array}$ \\
$\begin{array}{l}\text { Isabel Cristina Carmona (Colombia) } \\
\text { Anabella Mariani (Argentina) }\end{array}$ \\
Ana Paula Bortoletto Martins (Brasil)
\end{tabular}

* Os temas dos módulos foram mantidos no idioma original do curso.

O cursista recebeu, para cada aula, material de apoio para desenvolver a problematização que foi debatida com os demais cursistas. Além das horas de dedicação ao curso, foram acrescidas 24 horas à carga horária para estudo e participação no fórum, e mais 24 horas para planejamento e desenvolvimento do projeto final em segurança alimentar e nutricional no âmbito escolar, perfazendo uma carga horária total de 60 horas.

O certificado de finalização do curso foi entregue depois de comprovar a participação nas atividades online (fórum) e resposta dos questionários com pelo menos $75 \%$ de participação e com a entrega do projeto final, com nota maior ou igual a 7,0, que devia abordar uma proposta de ação em soberania, segurança e educação alimentar e nutricional, de extensão à comunidade escolar envolvendo, se possível, a participação das famílias voltadas ao espaço escolar. 


\section{Desenho, implementação e alcances de um curso internacional virtual sobre Segurança} Alimentar e Nutricional

A estrutura do curso Educa-SAN foi pensada pela equipe organizadora procurando abordar diversas temáticas associadas à SAN e o espaço escolar; para cada um dos módulos implementados foi escolhida uma metodologia que permitisse trabalhar da melhor forma os conteúdos e seu alcance nas escolas dos cursistas nos países envolvidos. Como três dos países tem o espanhol como língua oficial, optou-se por desenvolver o curso nesse idioma; considerando que os conteúdos pensados para os alunos brasileiros seriam em português. Mesmo assim, tendo acompanhamento tutorial e apoio da equipe organizadora, uma das dificuldades enfrentadas foi a evasão dos cursistas brasileiros.

Incialmente foram propostos onze módulos estruturantes do curso, porém, durante a fase de planejamento, alguns dos temas foram articulados e finalmente o curso foi oferecido em dez módulos (sendo nove temáticos e um avaliativo), com duração de uma semana entre cada módulo de aula. As videoaulas assíncronas e as videoconferências síncronas foram desenvolvidas por docentes e pesquisadores especialistas no conteúdo do módulo para o qual foram convidados; gravando as videoaulas pela plataforma Zoom e, preferencialmente, de curta duração, pois há melhor adesão dos cursistas a videoaulas que não ultrapassem trinta minutos (BARRÉRE et al., 2011 apud KOUMI, 2006). As videoconferências foram realizadas pela plataforma virtual NutriSSAN, uma ferramenta tecnológica desenvolvida pelo MCTI e a Rede Nacional de Ensino e Pesquisa (RNP) que promove a comunicação, interação e cooperação em rede para a Soberania e Segurança Alimentar e Nutricional (SSAN), articulando e integrando pesquisadores, extensionistas, estudantes e sociedade (RNP, 2021).

O curso ficou composto por três módulos de videoconferências síncronas (no início, no meio e no final do curso), um módulo teve apenas um vídeo geral em espanhol sobre o assunto, cinco módulos foram preparados com cinco vídeos (sendo um geral introdutório para o conteúdo e um vídeo específico para cada país) e o último módulo correspondeu à entrega dos projetos dos cursistas e avaliação do curso. Após a visualização das videoaulas, os estudantes deviam responder cinco questões sobre o tema do módulo em consonância com o contexto de seu país, sendo duas perguntas sobre o vídeo geral e três perguntas sobre o vídeo específico. Os módulos e suas metodologias foram:

Módulo 1: Videoconferência síncrona para apresentação do curso, do Moodle e uma breve contextualização da "Importância da Segurança Alimentar e Nutricional no espaço escolar: impactos da pandemia" e que permitiu articular os conceitos do curso com a pandemia da Covid- 
19 mediante a apresentação da importância dos programas nacionais de alimentação escolar neste período; assim como também, responder às dúvidas dos cursistas mediante áudio e/ou chat da NutriSSAN. Como atividades assíncronas, a gravação da videoconferência foi disponibilizada no Moodle para os cursistas que não conseguiram participar da sessão; também foi criado um fórum para apresentação de todos os participantes e uma pasta com materiais complementares.

Módulo 2: Abordagem do conteúdo sobre "Alimentação e cultura: as transformações dos alimentos, dos gostos e do corpo" mediante videoaulas assíncronas, sendo uma geral sobre a temática e um vídeo para cada país abordando as mudanças que têm acontecido na cultura alimentar latino-americana nos últimos séculos e os seus impactos na saúde das populações. Este módulo começou com a abertura dos fóruns para resolução de dúvidas e espaços de reflexão coletiva, e prosseguiu com a resolução de questionários sobre as videoaulas por parte dos cursistas.

Módulo 3: Videoaulas assíncronas, fórum e questionário sobre "Nutrientes essenciais: a utilização biológica dos alimentos e problemas de saúde decorrentes de práticas alimentares inadequadas". Na videoaula geral procurou-se abordar a importância dos macro e micronutrientes e, nos vídeos específicos, as problemáticas de saúde de cada país. O fórum teve uma alta participação dos cursistas, respondendo uma provocação associada ao consumo de nutrientes durante a pandemia.

Módulo 4: Videoconferência síncrona e fórum abordando "Políticas públicas sobre Segurança Alimentar e Nutricional no espaço escolar”. Foram convidados professores de cada um dos países para compartilharem as políticas existentes nos seus contextos, suas potencialidades, dificuldades e desafios. A discussão entre os palestrantes e cursistas permitiu perceber que as políticas públicas de SAN nos quatro países enfrentam desafios similares, sobretudo com a pandemia; o conceito de "sindemia"7 foi mencionado e colocado como um dos principais desafios para as políticas públicas, uma vez que existiria uma sindemia global de obesidade, subnutrição e mudança climática (SWINBURN, KRAAK, ALLENDER et al, 2019).

Módulo 5: Videoaulas assíncronas, fórum e questionário sobre "Guias alimentares para a população na América Latina como estratégias de comunicação, educação e promoção da saúde”. O módulo teve uma videoaula sobre a importância das guias e uma videoaula específica sobre a guia de cada país. Para a realização dos vídeos foram convidadas quatro professoras participantes do Grupo de Interesse Especial Guias Alimentares (SIG Guias Alimentares) ${ }^{8}$, uma rede virtual do CeLASSAN que reúne pesquisadores representantes de 18 países da América Latina para

\footnotetext{
${ }^{7}$ Conceito utilizado para designar uma sinergia de epidemias: como obesidade, desnutrição e mudanças climáticas, ocorrendo simultaneamente, interagindo entre si e compartilhando determinantes sociais.

${ }^{8}$ Este SIG, realizado por meio da plataforma NutriSSAN e Rede Nacional de Ensino e Pesquisa, foi proposto pelo CeLASSAN para problematizar questões referentes aos guias alimentares na perspectiva de uma rede contando com a participação de docentes e pesquisadores de 18 países da América Latina.
} 
desenvolver reflexões sobre a utilização das guias alimentares para o desenvolvimento de estratégias de maior divulgação e apropriação pelo público no contexto da soberania e segurança alimentar e nutricional.

Módulo 6: Videoaulas assíncronas, fórum e questionário sobre "Rotulagem nutricional como ferramenta de Segurança Alimentar e Nutricional”. Na videoaula geral procurou-se abordar a importância da leitura adequada e interpretação da rotulagem, para nas aulas específicas de cada país apresentar os tipos de rotulagem vigentes. No fórum foi destacada a importância da rotulagem frontal como uma ferramenta clara e promotora da saúde e na qual todos os países estão trabalhando.

Módulo 7: Neste módulo assíncrono procuramos que todos os cursistas pudessem conhecer "Estratégias de educação e promoção de hábitos de alimentação saudável nas escolas" dos quatro países para servirem como possíveis ideias de projetos finais dos cursistas; assim, as aulas, o questionário e o fórum procuraram abordar as estratégias de forma integrada e promovendo o intercâmbio de experiências.

Módulo 8: Módulo assíncrono com apenas uma videoaula sobre "Cardápios escolares: aproveitamento integral dos alimentos". Pensando no perfil dos nossos cursistas e no fato de que os quatro países possuem programas de alimentação para as escolas, na videoaula foram apresentados conteúdos sobre as necessidades nutricionais dos estudantes, a importância desses cardápios nos programas nacionais de alimentação escolar e a evidência científica sobre a relação de desempenho estudantil e boa alimentação.

Módulo 9: Última videoconferência síncrona do curso, abordando questões sobre a finalização do curso, projetos de intervenção e prazos; também foram discutidos assuntos relacionados diretamente com a atuação docente dentro das escolas: "Livros didáticos, currículo e percepção de professores sobre temas de alimentação". O professor convidado trouxe para a reflexão os resultados de uma pesquisa sobre o tema realizado tanto no Chile quanto no Brasil; países onde os livros didáticos e o currículo escolar abordam assuntos sobre SAN, porém, os docentes não possuem formação específica na área e devem procurar aprimoramentos por conta própria ou mesmo ensinar a partir da experiência pessoal (BACIGALUPO, 2015). No fórum da videoconferência os cursistas dos quatro países manifestaram ter vivenciado a mesma situação: devem preparar aulas e ministrar conteúdos sobre SAN que são exigidos no currículo escolar sem apresentarem ferramentas específicas para isso.

Módulo 10: Este módulo não apresentou conteúdo novo, mas o seu objetivo foi a oferta de um espaço para resolução de dúvidas sobre os projetos, atualização de pendências (fóruns, 
questionários ou vídeos), indicações sobre a entrega dos projetos e avaliação do curso mediante um questionário virtual.

\section{Os cursistas e os projetos de intervenção: a interdisciplinaridade dentro do espaço escolar.}

Freire (1987) nos alerta que a relação do sujeito com o seu próprio contexto, realidade e cultura é parte fundamental do processo de construção do conhecimento; problematizando, dialogando e sendo conscientes do que acontece ao nosso redor poderemos construir conhecimento engajado socialmente e transformador da realidade. $\mathrm{O}$ autor defende a superação do ensino disciplinar por meio de um trabalho interdisciplinar, mesmo não nomeando dessa forma nos seus escritos. De acordo com Lück (2010), a interdisciplinaridade:

[...] é o processo que envolve a integração e o engajamento de educadores, num trabalho conjunto, de interação das disciplinas do currículo escolar entre si e com a realidade, de modo a superar a fragmentação do ensino, objetivando a formação integral dos alunos, a fim de que possam exercer criticamente a cidadania, mediante uma visão global de mundo, e serem capazes de enfrentar os problemas complexos, amplos e globais da realidade atual (LÜCK, 2010, p. 47).

Nessa linha, se considerarmos que a Segurança Alimentar e Nutricional é uma temática que pode e deve ser abordada de forma interdisciplinar, no Educa-SAN procurou-se abrir espaços de participação não só para docentes das escolas, mas também para os diversos trabalhadores atuantes no espaço escolar. O perfil das mais de 200 pessoas que mostraram interesse no curso era diverso, passando por muitos tipos de professores (de línguas, química, física, biologia, educação física, filosofia etc.), funcionários administrativos das escolas (direção e secretarias), profissionais da saúde atuantes em escolas (nutricionistas, enfermeiros, psicólogos etc.), até funcionários das prefeituras interessados na implementação de ações nas escolas.

Dos 111 cursistas matriculados no curso, 27 deles conseguiram cumprir com os requisitos para aprovação, participando ativamente nas atividades preparadas para cada módulo no Moodle e completando-as em pelo menos 75\%. A distribuição dos aprovados, conforme os países, foi similar entre os hispanofalantes: dez cursistas da Argentina, sete cursistas do Chile e dez cursistas da Colômbia; infelizmente, como já foi mencionado, o fato de o curso ter sido idealizado em espanhol dificultou o acompanhamento das atividades e finalização do curso por parte dos cursistas brasileiros. No entanto, o perfil dos aprovados (quadro 2) representa a interdisciplinaridade proposta por Lück, uma vez que não apenas os docentes, mas diversos atores do espaço escolar se interessaram pela formação integral dos estudantes. 
Quadro 2: Perfil dos cursistas aprovados no curso Educa-SAN.

\begin{tabular}{|l|c|}
\hline Perfil dos cursistas & Número \\
\hline Professora de ensino fundamental & 10 \\
\hline Professora de ensino médio & 9 \\
\hline Diretora de escola & 2 \\
\hline Professora de ensino infantil & 2 \\
\hline Responsável de cantina escolar & 2 \\
\hline Assistente administrativo & 1 \\
\hline Docente de gastronomia & 1 \\
\hline
\end{tabular}

Mais uma amostra da interdisciplinaridade dos cursistas está no fato de que os 27 participantes aprovados apresentaram apenas 20 projetos de intervenção, ou seja, quatro deles foram realizados por dois ou mais cursistas da mesma escola. Por outro lado, quatro projetos foram realizados no formato visual, isto é, com cartazes promovendo alguma atividade ou conceito; um projeto teve o formato de um vídeo explicativo sobre hortas e cuidados com o meio ambiente e 15 foram projetos escritos com propostas de intervenção bem delineadas. Ao analisar as temáticas dos projetos realizados pelos cursistas como requisito parcial para conclusão do curso, identificamos algumas caraterísticas comuns que foram agrupadas em oito categorias relativas às temáticas do curso (quadro 3):

Quadro 3: Temáticas dos projetos desenvolvidos pelos cursistas.

\begin{tabular}{|c|c|}
\hline Temáticas & Número \\
\hline Alimentação saudável & 6 \\
\hline Guias alimentares & 3 \\
\hline Horta & 3 \\
\hline Nutrientes & 3 \\
\hline Alimentação escolar & 2 \\
\hline Classificação NOVA & 1 \\
\hline Cultura e culinária & 1 \\
\hline Oficina culinária & 1 \\
\hline
\end{tabular}


Alimentação escolar: Categoria de dois projetos que centralizavam suas propostas de intervenção dentro das ações já estabelecidas pelo programa nacional de alimentação escolar. Utilizando a cozinha e cantinas das escolas, os projetos propõem realizar oficinas com pessoal das escolas, pais e estudantes, trabalhando diversas temáticas atreladas à alimentação escolar e ao conteúdo do curso.

Alimentação saudável: Seis projetos entraram nesta categoria, na qual reunimos uma miscelânea de sub-temáticas, mas todas tendo como fio condutor a alimentação saudável ou mesmo as diferenças entre alimentação e nutrição; por exemplo, uma proposta de intervenção na escola para venda de espetinhos de frutas pelos mesmos estudantes, um projeto para identificar mediante um questionário virtual as temáticas mais importantes sobre alimentação na comunidade escolar, outro sobre criação de uma cantina saudável na escola etc.

Classificação NOVA: Pelo menos três projetos aludem à classificação NOVA como uma forma de promover uma alimentação saudável, mas apenas um dos projetos faz da classificação o núcleo central da proposta de intervenção: avaliar em conjunto com os estudantes da escola o nível de processamento dos alimentos oferecidos pela cantina escolar e pelas lanchonetes ao redor da escola. Resulta interessante ver que uma docente colombiana tenha adotado como temática principal um conceito apresentado no Brasil: Monteiro et al. (2010) propuseram uma nova classificação dos alimentos baseada no processamento industrial que resultou em três grupos (modificados para a segunda edição do guia alimentar brasileiro, passando para quatro grupos): alimentos in natura ou minimamente processados, ingredientes culinários (descritos no Guia como grupo dos óleos, gorduras, sal e açúcares), alimentos processados e alimentos ultraprocessados (MENEGASSI, ALMEIDA e OLIMPIO, 2018).

Cultura e culinária: Um dos projetos da Argentina abordou como temática central a recuperação da cultura alimentaria, as tradições e as preparações culinárias. Assim, o projeto articula considerações feitas no Módulo 2 do curso e o contex to sociocultural da escola.

Guias alimentares: Para três dos nossos cursistas (dois da Argentina e um da Colômbia) o guia alimentar para a população foi o eixo central das suas propostas. Muitas vezes desconhecidos pela população para a qual foram criados, os guias alimentares são instrumentos de orientação alimentar e valorização de culturas e práticas alimentares. Os guias podem relacionar aspectos sociais, culturais, nutricionais, higiênico-sanitários, considerando também a advocacia na promoção da saúde, para um consumo alimentar saudável e seguro em quantidade e qualidade para a população e que garanta o direito humano à alimentação adequada. 
Horta: Como parte das experiências educativas apresentadas no Módulo 7, a horta teve uma grande projeção por parte dos cursistas: três projetos articulavam atividades de alimentação saudável ao desenvolvimento de uma horta escolar. Coelho e Bógus (2016) afirmam que a existência de uma horta escolar "permite estabelecer uma relação diferente com os alimentos, por meio do despertar da curiosidade para sua produção, por meio do conhecimento da cadeia alimentar e a "origem dos alimentos".

Nutrientes: De acordo com as discussões no fórum, os nutrientes representam uma das temáticas mais conhecidas pelos cursistas, no entanto, a especificidade sobre quais alimentos aportam determinados nutrientes e a sua importância no desenvolvimento dos estudantes constituíram uma das principais propostas que apareceram nos três projetos dentro desta categoria.

Oficina culinária: Um dos projetos apresentados em formato de cartaz promove a realização de uma "oficina de segurança alimentar e nutricional" na qual os estudantes do ensino fundamental colocarão em prática os conhecimentos sobre nutrientes e meio ambiente ao preparar uma salada ou espetinhos de frutas, procurando que esses alimentos sejam realmente uma opção para eles ao manuseá-los e experimentá-los.

\section{Conclusão}

O Educa-SAN foi idealizado como um curso de atualização em Segurança Alimentar e Nutricional para os integrantes das comunidades educativas de Argentina, Brasil, Chile e Colômbia utilizando as potencialidades das TICs no ensino-aprendizagem, com boa participação nos fóruns, nos encontros síncronos e na finalização das atividades; considerando ainda que no ano de 2020 enfrentamos uma série de obstáculos produzidos pela pandemia, um deles foi a conversão de grande parte das atividades cotidianas de trabalho, de estudo e de lazer para o ambiente virtual causando uma sobrecarga e um estresse físico, emocional e mental.

Assim como muitos dos nossos cursistas reconheceram que os hábitos de alimentação saudável (ou não) são produto das experiências nos lares dos estudantes, também reconhecemos na escola um espaço de sociabilização de estilos de vida saudável. A interdisciplinaridade na abordagem destas questões no espaço escolar e o envolvimento dos pais dos estudantes são nós críticos que devemos considerar e abordar em possíveis futuras versões do curso.

Com os resultados obtidos no questionário de avaliação do Módulo 10, percebemos que a escolha da estratégia metodológica contribuiu para aprimorar o diálogo entre os cursistas internacionais, permitindo abrir nos fóruns espaços de reflexão coletiva em que os cursistas e os docentes da ação compartilharam seus próprios saberes pedagógicos, metodológicos e os seus próprios conhecimentos sobre o que se entende por Segurança Alimentar e Nutricional. 


\section{Referências}

ARGENTINA. Ley $\mathbf{N}^{\mathbf{0}} \mathbf{2 6 . 3 9 6}$, de 03 de setembro de 2008. Aprova a política nacional argentina para a prevenção e tratamento da obesidade. Buenos Aires, 2008.

BACIGALUPO, J. Análisis comparativo de materiales didácticos y percepciones de profesores acerca de alimentación y nutrición en las comunas de Puente Alto, Santiago de Chile y Foz de Iguazú, Brasil. Monografía (Saúde Coletiva). Universidade Federal da Integração Latino-Americana. Foz do Iguaçu, p. 129. 2015. Disponível em: https://dspace.unila.edu.br/handle/123456789/391. Acesso em: 20 nov. 2018.

BELLONI, M.L. Educação a Distância. 5. Ed. Campinas, SP: Autores Associados, 2008.

BOOG, M.C.F.. Programa de educação nutricional em escola de ensino fundamental de zona rural. Rev. Nutr., Campinas, v. 23, n. 6, p. 1005-1017, Dec. 2010.

BRASIL. Ministério da Saúde. Portaria Interministerial n 1010. Brasília, DF: 2006. Disponível em: http://bvsms.saude.gov.br/bvs/saudelegis/gm/2006/pri1010_08_05_2006.html. Acesso em: 20 nov. 2018.

—. Lei $\mathbf{n}^{\mathbf{0}}$ 11.947. Brasília, DF: 2009. Disponível em: http://www.planalto.gov.br/ccivil_03/_Ato2007-2010/2009/Lei/L11947.htm. Acesso em: 22 nov. 2018.

Câmara Interministerial de Segurança Alimentar e Nutricional. Plano Nacional de Segurança Alimentar e Nutricional - PLANSAN 2016-2019. Brasília, DF: 2017. Disponível em:

https://www.mds.gov.br/webarquivos/arquivo/seguranca_alimentar/caisan/plansan_2016_19.pdf. Acesso em: 23 nov. 2018.

- Lei $\mathbf{n}^{\mathbf{0}}$ 13.666. Brasília, DF: 2018. Disponível em: http://www.planalto.gov.br/ccivil_03/_ato2015-2018/2018/lei/L13666.htm. Acesso em: 12 de janeiro de 2021.

Ministério da Transparência e Controladoria-Geral da União. Secretaria de Transparência e Prevenção da Corrupção Diretoria de Transparência e Controle Social Coordenação-Geral de Governo Aberto e Transparência. 4 Plano de Ação Nacional em Governo Aberto. Brasília, 2018. Disponível em: https://www.gov.br/cgu/pt-br/governo-aberto/aogp/planos-de-acao/4o-plano-de-acao-brasileiro/4o-plano-de-acao-nacional_portugues.pdf.

Acesso em: 13 de jan 2021.

CARTA DE OTTAWA. In: $\mathbf{1}^{\text {a }}$ Conferência Internacional sobre Promoção da Saúde. Ottawa, Canadá; 1986. Disponível em: http://bvsms.saude.gov.br/bvs/publicacoes/carta_ottawa.pdf . Acesso em: 06 março 2020.

CHILE. Ministerio de Salud. Ley No 20.606. Santiago de Chile: 2012. Disponível em: https://www.leychile.cl/Navegar?idNorma=1041570. Acesso em: 24 nov. 2018. 
COELHO, D.; BOGUS, C. Vivências de plantar e comer: a horta escolar como prática educativa, sob a perspectiva dos educadores. Saude soc. São Paulo, v. 25, n. 3, p. 761-770, Sept. 2016. Disponível em: <http://www.scielo.br/scielo.php?script=sci_arttext\&pid=S0104$12902016000300761 \& \operatorname{lng}=$ en \&nrm=iso $>$. Acesso em 30 jan. 2021.

COLOMBIA. Ley 1355 de 14 de octubre de 2009. Lei da Obesidade. Bogotá, Colombia.

CONTRERAS, J; GRACIA-ARNAIZ, M. Alimentação, sociedade e cultura. Rio de Janeiro: Editora Fiocruz, 2011.

DEClARAÇÃO DE XANGAI. In: $9^{a}$ Conferência Global de Promoção da Saúde. Xangai, China; 2016. Disponível em: http://dssbr.org/. Acesso em: 06 março 2020 .

FLORIANÓPOLIS. Plano de formação permanente na modalidade de educação a Distância da secretaria municipal de educação de Florianópolis. 2014. Disponível em: http://portal.pmf.sc.gov.br/arquivos/arquivos/pdf/06_03_2018_16.26.33.eb93f79545838d3810f3 17b274ac20d5.pdf. Acesso em: 26 nov. 2018.

FREIRE, P. Pedagogia da Autonomia: saberes necessários à prática educativa. Coleção Leitura. $31^{\text {a }}$ ed. São Paulo: Paz e Terra, 1996.

FREIRE, P. Pedagogia do oprimido. $17^{\text {a }}$ ed. Rio de Janeiro, Paz e Terra, 1987.

GONZÁLEZ, J. F. Estrategia metodológica mediada por la plataforma Moodle para la enseñanza-aprendizaje de los conceptos de distancia, desplazamiento, velocidad y aceleración en los estudiantes de grado décimo. Medellín: Universidad Nacional de Colombia. Facultad de Ciencias, 2013.

GONZALEZ-CHICA, D.A. et al. Percepção dos cozinheiros escolares sobre o processo de utilização de produtos orgânicos na alimentação escolar em municípios catarinenses. Rev. Nutr., Campinas, v. 26, n. 4, p. 407-418, Aug. 2013.

KOUMI, J.. Designing video and multimedia for open flexible learning. New York: Routledge, 2006.

LÜCK, H.. Pedagogia interdisciplinar: fundamentos teórico-metodológicos. Rio de Janeiro: Vozes, 2010.

MENEGASSI, B.; ALMEIDA, J.; OLIMPIO, M.Y. et al. A nova classificação de alimentos: teoria, prática e dificuldades. Ciênc. saúde coletiva, Rio de Janeiro , v. 23, n. 12, p. 41654176, Dec. 2018. Disponível em: <http://www.scielo.br/scielo.php?script=sci_arttext\&pid=S141381232018001204165\&lng=en\&nrm=isso. Acesso em: 30 jan. 2021.

MONTEIRO C.A., LEVY R., CLARO R. et al. A new classification of foods based on the extent and purpose of their processing. Cad Saude Publica. 2010; 26(11): 2039-2049. Disponível em: https://www.scielo.br/scielo.php?script=sci_arttext\&pid=S0102-311X2010001100005. Acesso em: 25 jan. 2021.

ONU. Nações Unidas no Brasil. Objetivos de desenvolvimento sustentável. 2018. Disponível em: https://nacoesunidas.org/pos2015/agenda2030/. Acesso em: 25 nov. 2018.

PORVIR. Ensino Híbrido ou Blended Learning. 2013. Disponível em: <http://porvir.org/ensino-hibrido-ou-blended-learning/ >. Acesso em: 29 nov. 2018. 
RECH, J.; SOARES, E.M.S; VALENTINI, C.B; Convivência e aprendizagem em ambientes virtuais: uma reflexão a partir da biologia do conhecer. Educ. rev., Belo Horizonte, v. 27, n. 3, p. 39-59, Dec. 2011. Disponível em: $<$ http://www.scielo.br/scielo.php?script=sci_arttext\&pid=S0102$46982011000300003 \& \operatorname{lng}=e n \& n r m=i s o>$. Acesso em: 26 nov. 2018.

RNP. Rede Nacional de Ensino e Pesquisa. Ministério da Ciência, Tecnologia e Inovações. 2021. Disponível em https://nutrissan.rnp.br. Acesso em: 20 jan. 2021.

SILVA, M.R; MACIEL, C. Blended learning: reflexões sobre o ensino semipresencial na educação superior no brasil. XII Congresso Brasileiro de Educação. 2015. Disponível em: http://educere.bruc.com.br/arquivo/pdf2015/20231_9663.pdf. Acesso em: 29 nov. 2018.

SOUZA, A.; LIRA, J. Concepções Freirianas sobre as TICs e a Educação a Distância. $3^{\circ}$ Simpósio Hipertexto e Tecnologia da Educação. Recife: Universidade Federal de Pernambuco - Núcleo de Estudos de Hipertexto e Tecnologias na Educação. 2010. Disponível em: http://www.nehte.com.br/simposio/anais/Anais-Hipertexto-2010/Avanisia-Souza.pdf. Acesso em: 24 nov. 2018.

SWINBURN, B.; KRAAK, V.; ALLENDER, S., et al. The Global Syndemic of Obesity, Undernutrition, and Climate Change: The Lancet Commission report. Lancet 2019. Disponível em: https://www.thelancet.com/commissions/global-syndemic. Acesso em: 30 jan. 2021.

VYGOTSKY, L.S. A formação social da mente - o desenvolvimento dos processos psicológicos superiores. São Paulo: Martins Fontes, 1991.

\section{Agradecimentos:}

Aos cursistas que enriqueceram os debates sobre SAN a partir do compartilhamento de suas experiências possibilitando a consolidação do curso e instigando a realização de ações futuras.

À bolsista e às voluntárias da ação de extensão pelo valioso apoio técnico e acompanhamento dos cursistas.

Às docentes: Ana Virginia Asaduroglu, da Universidad Nacional de Córdoba, Bernardita Daniels e Paola Cáceres da Universidad de Chile e Luz Marina Arboleda Montoya da Universidad de Antioquia pelas inestimáveis contribuições no planejamento e desenvolvimento desta ação.

Aos docentes e aos pesquisadores que ajudaram a fortalecer o curso com a apresentação das videoaulas problematizando temáticas necessárias e urgentes à SAN no contexto escolar.

À Pró-Reitoria de Extensão da Universidade Federal da Integração Latino-Americana pelo registro da ação de extensão, pelo constante apoio na gestão do Moodle e pela crença no ensino plural.

Ao Ministério de Ciência, Tecnologia e Inovações pelo apoio financeiro.

Recebido em: 19/12/2020 Aprovado em 05/02/2021 